\title{
Trust in Vaccination as a Factor in Public Health During a Pandemic
}

http://doi.org/10.21272/bel.5(4).90-100.2021

Olha Kuzmenko, ORCID: https://orcid.org/0000-0001-8575-5725

Doctor of Economics, Professor, Sumy State University, Ukraine

Svitlana Kolomiiets, ORCID: https://orcid.org/0000-0002-7832-8415

$\mathrm{PhD}$, Associate professor, Sumy State University, Ukraine

\begin{abstract}
The article summarizes the arguments in the scientific debate on public trust in vaccination against COVID-19. The main purpose of the research is to model the trend of changes in the trust in vaccination against COVID-19, analyzing time series by exponential smoothing. The object of the study is the public trust in vaccination against COVID-19. The research aims to model the changing trend of the trust in the vaccination against COVID-19 using time series analysis. Systematization of literature sources and approaches to solving the vaccination problem during the pandemic showed that various psychological, social, economic factors, including trust in official information, affect the level of trust in vaccination. Declining confidence in the authorities, medical institutions, social institutions, and the media significantly impacts the effectiveness of pandemic containment measures. The trust of the population in state institutions in scientifically based information on vaccination provides the necessary level of vaccination during the COVID-19 pandemic. The study regarding the changing trend in the level of trust in vaccination against COVID-19 analyzing time series by exponential smoothing in the article is carried out in the following logical sequence: 1) Internet users on the issues of "Trust in vaccination against COVID-19", "Vaccination against COVID-19", "Trust in vaccination" was carried out using Google Trends; 3) Statistica software package was used to implement exponential smoothing models. Predictive models of exponential smoothing based on the following indicators: "Trust in vaccination against COVID-19", "Trust in vaccination", "Vaccination against COVID-19" are constructed. Time series models related to public confidence in COVID-19 vaccination demonstrate the presence of a seasonal component every two weeks. The results of the study can be useful for the development of scientifically sound recommendations to control the vaccination process during a pandemic, to build predictions of the level of trust in vaccination against COVID-19.
\end{abstract}

Keywords: COVID-19, Exponential Smoothing, Google Trends, Time Series, Trust, Vaccination.

JEL Classification: C22, I15, I18.

Cite as: Kuzmenko, O., Kolomiiets, S. (2021). Trust in Vaccination as a Factor in Public Health During a Pandemic. Business Ethics and Leadership, 5(4), 90-100. http://doi.org/10.21272/bel.5(4).90-100.2021.

Received: 14 October 2021

Accepted: 04 December 2021

Published: 30 December 2021

Copyright: (C) 2021 by the author. Licensee Sumy State University, Ukraine. This article is an open access article distributed under the terms and conditions of the Creative Commons Attribution (CC BY) license (https://creativecommons.org/licenses/by/4.0/).

\section{Introduction}

Vaccination of the population is one of the most effective methods for preventing the COVID-19 pandemic spread. The vaccination process is crucial to preserve human capital and the economy. The success of the vaccination in different countries, including Ukraine, is primarily determined by people's willingness to be vaccinated. In Ukraine, vaccination officially began on February 24, 2021. According to minfin.com.ua, as of December 7, 2021, 33.65\% of the population in Ukraine has been vaccinated, and $29.14 \%$ have been fully vaccinated. Vaccination strategies and goals are gradually being transformed by shifting the focus from reducing mortality and burdening health facilities to the vaccination impact on economic and public constraints. Understanding the economic, political, and social factors that influence the effective deployment of the vaccination process, the decision-making of the population on vaccination requires special attention. Negative perceptions of the immunization campaign and infodemia are significant threats to personal vaccination decisions. Doubts about vaccination against COVID-19 are common and a disincentive to combat the pandemic around the world. The spread of conspiracy theories and unscientific information through social 
networks has led to public rejection of the COVID-19 pandemic, threatening the vaccination process. During the pandemic, the population's level of anxiety and uncertainty is growing. If official sources of information are not credible, the lack of knowledge is quickly filled by conspiracy theories and the emergence of "antivaccine" movements. The trust of the population in state institutions in scientifically-based information on vaccination provides the necessary level of vaccination during the COVID-19 pandemic. Study of the factors influencing the credibility of vaccination against COVID-19, modeling the level of public trust in vaccination, and developing scientifically sound recommendations to control the vaccination process during a pandemic is an urgent task.

\section{Literature Review}

The trust in vaccination against COVID-19 has become relevant since the development of the vaccine. According to WHO experts (Behavioral considerations for acceptance and uptake of COVID-19 vaccines, 2020), after solving the problems regarding sufficient production of new vaccines, effective vaccination organization, and ensuring fair access to vaccines, a set of measures to build trust in vaccines and people's readiness for vaccinations will be necessary to implement. According to researchers (Karlsson et al., 2020), in the situation of coronavirus vaccination, it is important how much a person trusts the source of information about the importance and safety of vaccination, how they compare the risks and benefits of vaccination. To clarify the research on the problem of trust in vaccination against COVID-19 by scientists from different countries, an analysis of literature was conducted by a bibliography of the term "COVID-19" in recent years, using recent literature VOSViewerv.1.6.10. The research results are presented in Fig.1.

Analysis of Fig. 1 shows that research on the COVID-19 pandemic, vaccination against COVID-19, and credibility for vaccination during the COVID-19 pandemic has received considerable attention from scientists. Special attention will be paid to studying factors influencing public confidence in vaccination in general and vaccination against COVID-19. According to researchers (Karlsson et al., 2020), in coronavirus vaccination, it is important how much a person trusts the source of information about the importance and safety of vaccination, how he compares the risks and benefits of vaccination. The research (Makusheva and Nestik, 2020) analyzes the socio-psychological preconditions and effects of trust in social institutions in a pandemic. A comprehensive analysis of societal attitude to vaccination against COVID-19 in some CAREC countries was conducted in work (Societal attitudes analysis to vaccination against COVID-19 in selected CAREC countries, 2021). Researchers (Vdovychenko and Zosymenko, 2021) studied the influence of political, economic, and social factors on the management and effective course of immunization campaigns in response to the pandemic on the example of EU countries.

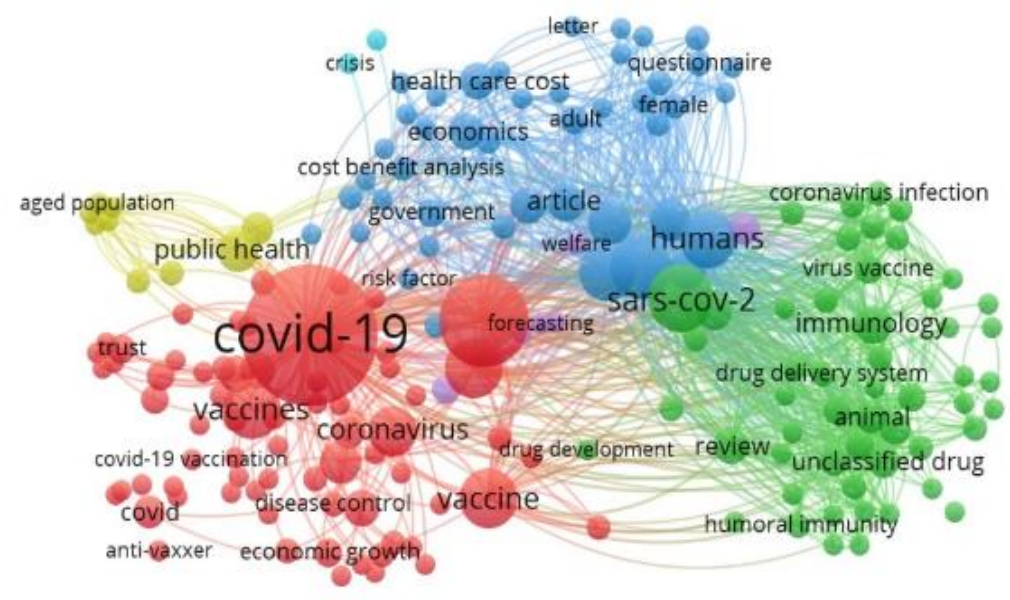

Figure 1. Scientific Bibliography of the Concept "COVID-19" in Recent Years Using the Vosviewerv.1.6.10 Program Source: Compiled by the authors based on Scopus publications for 2020-2021

Scientists from Ukraine and around the world pay significant attention to monitoring the population's attitude to vaccination. In particular, the study (Boyon, 2020) analyzes factors influencing vaccination refusal, namely doubts about the quality of the vaccine, distrust of clinical trials, fears of side effects due to vaccination. (Lazarus et al., 2021) determines factors influencing the readiness for vaccination. Sociological research has shown that the preparedness for vaccination depends on the level of trust in the government. A subjective readiness for vaccination against COVID-19 and factors influencing the refusal of vaccination were observed 
in work (Rasskazova et al., 2021). Attitudes towards vaccination in general, towards vaccination against COVID-19, ways to promote trust in vaccination against COVID-19 are studied in the paper (Steven et al., 2020). Researchers (Tkhostov et al., 2020) check the link between pandemic anxiety and the search for information about the coronavirus and protective actions. The results demonstrate that targeted control of information flow can help reduce pandemic anxiety and increase trust in vaccination. An analysis of scientific publications in recent years has shown that considerable attention has been paid to studying factors influencing public trust in COVID-19 vaccination. The main research methods in the works are statistical analysis of the respondents' survey results. Despite numerous publications regarding the trust in vaccination against COVID-19, it requires further in-depth research, especially in predicting the level of vaccination trust. The aim of the work is to study the trends in the level of trust in the vaccination against COVID-19 by analyzing time series using the exponential smoothing method.

\section{Methodology and Research Methods}

The analysis of time series through exponential smoothing is proposed by implementing the following stages.

Formation of the input base of the study. At this stage, the quantitative feature in assessing trust trends in the vaccination against COVID-19 is identified. It occurs by determining the levels of the time series of Internet users' requests for the concepts "vaccination against COVID-19", "trust in vaccination against COVID-19", "trust in Vaccination" with Google Trends. For this stage, the period from December 2018 to December 2021 was considered for many countries around the world.

$>$ Research of the dynamics of the time series behavior in the number of Internet users' requests for the concepts "vaccination against COVID-19", "trust in vaccination against COVID-19", "trust in vaccination" through exponential smoothing method.

The main advantage of the predictive model, which is obtained using the exponential smoothing method, is that it can consistently adapt to a new process level without a significant response to random deviations. The exponential smoothing method uses a weighted (exponential) moving average of all data from previous observations, and the weight values decrease exponentially as you move away from the current point. Exponential smoothing is an assessment of the current state, the results of which determine all subsequent forecasts. Exponential smoothing involves constantly updating the model with the latest data. The exponential smoothing procedure is described by the formula:

$$
Y_{t}=\alpha \cdot X_{t}+(1-\alpha) \cdot Y_{t-1}
$$

where $X_{t}-$ the level of the time series at the time $\mathrm{t}$;

$\alpha$ - smoothing parameter, $0<\alpha<1,(1-\alpha)$ - discount rate

$Y_{t}, Y_{t-1}-$ exponentially smoothed value at a time $t$ and $t-1$ accordingly.

Exponential smoothing works as a filter, the input of which successively receives members of the input series, and the output is formed values of exponential averages. Moreover, the smoothed series $Y_{t}$ has the same mathematical expectation as the series $X_{t}$, but less variance. In addition to exponential smoothing, more complex models are used that contain a trend and a seasonal component. The general idea of using such models is that forecasts are calculated not only from previous observations but also with some delays, which allows you to assess the trend independently and the seasonal component. We use the following formulas to build predictions of exponential smoothing based on time series models without a trend:

additive model:

$$
\begin{gathered}
P_{t}=Y_{t}+I_{t-p} \\
I_{t}=I_{t-p}+\delta \cdot(1-\alpha) \cdot e_{t}
\end{gathered}
$$

multiplicative model:

$$
\begin{gathered}
P_{t}=Y_{t} \cdot I_{t-p} \\
I_{t}=I_{t-p}+\delta \cdot(1-\alpha) \cdot \frac{e_{t}}{Y_{t}}
\end{gathered}
$$

where $\delta$ - the seasonal smoothing parameter, specified only for seasonal models; $Y_{t}-$ a simple exponentially smoothed value of the time series at time $t$; 
$I_{t-p}$ - smoothed seasonal factor at time $t-p$, where $p$ is the length of the season;

$e_{t}-$ rests at time t.

In the case of models with a linear and exponential trend, the specified trend is added to models (2) or (3).

The smoothing values for the first season are additionally calculated based on the initial values for the seasonal components to build exponential smoothing forecasts based on time series models that contain an exponential trend and a seasonal additive component. Estimates $S_{0}$ (initial seasonal component) and $T_{0}$ (initial trend) use the following formulas to calculate the smoothed value for the first observation:

$$
\begin{gathered}
T_{0}=\exp \left(\frac{\left(\log \left(M_{k}\right)-\log \left(M_{1}\right)\right)}{p}\right) \\
S_{0}=\exp \left(\left(\log \left(M_{1}\right)-p \cdot \log \left(T_{0}\right) / 2\right)\right)
\end{gathered}
$$

where $\mathrm{k}$ - the number of complete seasonal cycles;

$M_{k}$ - the average value for the last seasonal cycle;

$M_{1}-$ average value for the first seasonal cycle;

$p$ - the duration of the seasonal cycle.

The smoothing values for the first season are additionally calculated based on the initial values for the seasonal components to build exponential smoothing forecasts based on time series models that contain the exponential trend and a multiplicative seasonal component. Estimates $S_{0}$ (initial seasonal component) and $T_{0}$ (initial trend) use the following formulas to calculate the smoothed value for the first observation:

$$
\begin{gathered}
T_{0}=\exp \left(\frac{\left(\log \left(M_{2}\right)-\log \left(M_{1}\right)\right)}{p}\right) \\
S_{0}=\exp \left(\left(\log \left(M_{1}\right)-p \cdot \log \left(T_{0}\right) / 2\right)\right)
\end{gathered}
$$

where $M_{2}$ - the average value for the second seasonal cycle;

$M_{1}$ - average value for the first seasonal cycle.

It is necessary to calculate smoothed values for the first season based on initial values for seasonal components to construct exponential smoothing forecasts based on time series models that contain linear trend and a multiplicative seasonal component Estimates $S_{0}$ (initial seasonal component) and $T_{0}$ (initial trend) use the following formulas to calculate the smoothed value for the first observation in the series:

$$
\begin{aligned}
T_{0} & =\frac{M_{k}-M_{1}}{(k-1) \cdot p} \\
S_{0} & =M_{1}-p \cdot \frac{T_{0}}{2}
\end{aligned}
$$

The smoothed values for the first season, based on the initial values for seasonal components are calculated to build exponential smoothing forecasts based on time series models that contain a damped (decaying) trend and a seasonal additive component, as in previous cases, according to the formulas:

$$
\begin{gathered}
T_{0}=\frac{1}{\phi} \cdot \frac{M_{k}-M_{1}}{(k-1) \cdot p} \\
S_{0}=M_{1}-p \cdot \frac{T_{0}}{2}
\end{gathered}
$$

where $\phi-$ the trend smoothing parameter used in the case of models with a decaying trend.

3. Statistica software package is used to implement exponential smoothing models: Statistics/Advanced linear/ Nonlinear Models/Time Series/Forecasting/Exponential Smoothing and Forecasting.

\section{Results}

The practical implementation of the exponential smoothing method for modeling the trust level in vaccination against COVID-19 was carried out in accordance with the proposed methodology. The dynamics of the number 
of requests from Internet users on the concept "Trust in vaccination against COVID-19" using Google Trends from December 2018 to December 2021 is presented in Figure 2.

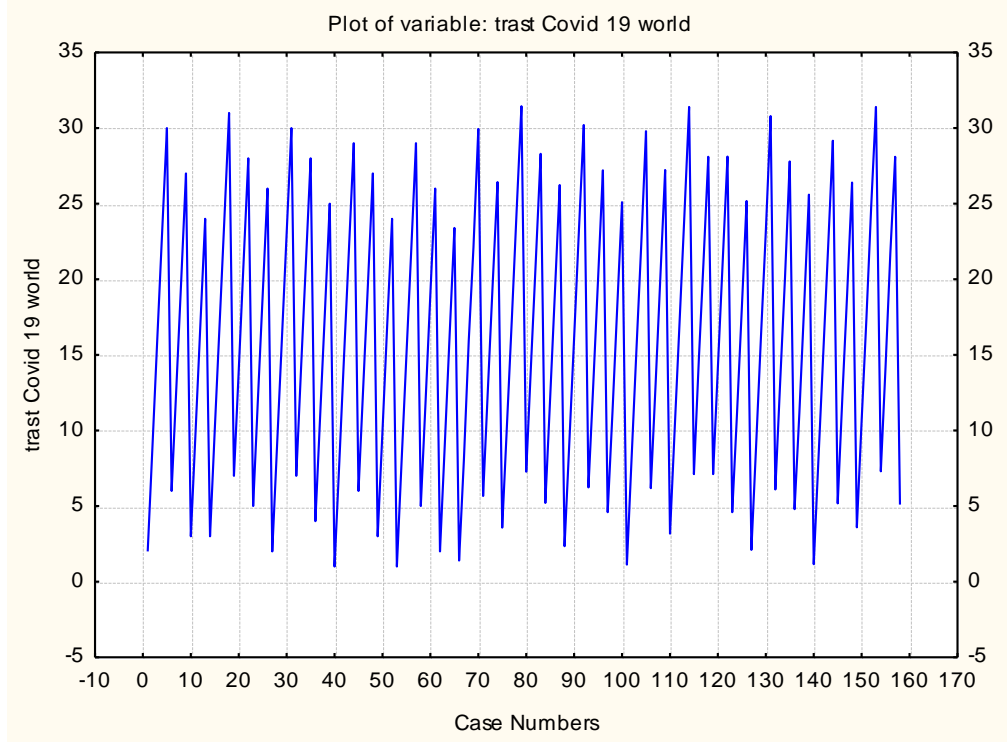

Figure 2. Dynamics of the Number of Internet Users' Inquiries on the Concept "Trust in Vaccination against COVID-19" Source: Compiled by the authors

Analysis of Figure 2 reveals a seasonal component in the time series "Trust in vaccination against COVID-19". Analysis of the dynamics of changes in the number of Internet users' requests for the concepts "Trust in vaccination" and "Vaccination against COVID-19" also showed seasonal components in the relevant time series. All three-time series show a similar dynamic of changes in the number of Internet users' requests. The implementation of the method of exponential smoothing in the software package Statistica allowed to obtain predictive models. The forecast models found will be presented in tabular form.

Table 1. Forecast Models of Exponential Smoothing of Statistical Indicators ("Trust in Vaccination against COVID-19", "Trust in Vaccination", "Vaccination against COVID-19")

\begin{tabular}{|c|c|c|}
\hline Indicator & & Model \\
\hline \multirow[t]{6}{*}{ Trust Covid 19} & TC 1 & $\begin{array}{l}\text { Exponential smoothing: Additive season (24) } \mathrm{S} 0=15,92 \\
\text { No trend,add.season; Alpha }=0,00 \text { Delta }=0,00\end{array}$ \\
\hline & TC 2 & $\begin{array}{l}\text { Exp. smoothing: Additive season (24) } \mathrm{S} 0=15,41 \mathrm{~T} 0=, 0071 \text { Lin.trend,add.season; Alpha }=0,00 \\
\text { Delta }=0,00 \text { Gamma }=0,00\end{array}$ \\
\hline & TC3 & $\begin{array}{l}\text { Exp. smoothing: Additive season (24) } \mathrm{S} 0=15,06 \mathrm{~T} 0=1,002 \text { Expon.trend,add.season; Alpha }=0,00 \\
\text { Delta }=0,00 \text { Gamma }=1 \text {, }\end{array}$ \\
\hline & TC4 & $\begin{array}{l}\text { Exponential smoothing: Multipl. season (24) } \mathrm{S} 0=15,92 \\
\text { No trend,mult.season; Alpha }=0,00 \text { Delta }=0,00\end{array}$ \\
\hline & TC5 & $\begin{array}{l}\text { Exp. smoothing: Multipl. season (24) } \mathrm{S} 0=15,41 \mathrm{~T} 0=, 0071 \text { Lin.trend,mult.season; Alpha }=0,00 \\
\text { Delta }=0,00 \text { Gamma }=0,00\end{array}$ \\
\hline & TC6 & $\begin{array}{l}\text { Exp. smoothing: Multipl. season (24) } \mathrm{S} 0=15,06 \mathrm{~T} 0=1,002 \text { Expon.trend,mult.season; Alpha }=, 012 \\
\text { Delta }=0,00 \text { Gamma }=, 086\end{array}$ \\
\hline \multirow[t]{5}{*}{ Trust vaccination } & TV1 & $\begin{array}{l}\text { Exponential smoothing: Additive season (24) } \mathrm{S} 0=15,38 \\
\text { No trend,add.season; Alpha }=0,00 \text { Delta }=0,00\end{array}$ \\
\hline & TV2 & $\begin{array}{l}\text { Exp. smoothing: Additive season (24) } \mathrm{S} 0=15,47 \mathrm{~T} 0=, 0066 \text { Lin.trend,add.season; Alpha }=0,00 \\
\text { Delta }=0,00 \text { Gamma }=0,00\end{array}$ \\
\hline & TV3 & $\begin{array}{l}\text { Exp. smoothing: Additive season (24) } \mathrm{S} 0=15,41 \mathrm{~T} 0=, 0113 \\
\text { Damped trend,add.season; Alpha }=0,00 \text { Delta }=0,00 \mathrm{Phi}=, 581\end{array}$ \\
\hline & TV4 & $\begin{array}{l}\text { Exponential smoothing: Multipl. season (24) } \mathrm{S} 0=15,38 \\
\text { No trend,mult.season; Alpha }=0,00 \text { Delta }=0,00\end{array}$ \\
\hline & TV5 & $\begin{array}{l}\text { Exp. smoothing: Multipl. season (24) } \mathrm{S} 0=15,47 \mathrm{~T} 0=, 0066 \text { Lin.trend,mult.season; Alpha }=0,00 \\
\text { Delta }=0,00 \text { Gamma }=0,00\end{array}$ \\
\hline \multirow[t]{3}{*}{ Covid vaccine } & $\mathrm{VC} 1$ & $\begin{array}{l}\text { Exponential smoothing: Additive season (24) } \mathrm{S} 0=16,03 \\
\text { No trend,add.season; Alpha }=0,00 \text { Delta }=0,00\end{array}$ \\
\hline & $\mathrm{VC} 2$ & $\begin{array}{l}\text { Exp. Smoothing: Additive season (24) } \mathrm{S} 0=15,38 \mathrm{~T} 0=, 0103 \text { Lin.trend,add.season; Alpha }=0,00 \\
\text { Delta }=0,00 \text { Gamma }=0,00\end{array}$ \\
\hline & VC3 & $\begin{array}{l}\text { Exp. Smoothing: Additive season (24) } \mathrm{S} 0=15,06 \mathrm{~T} 0=1,002) \text { Expon.trend,add.season; Alpha }=0,00 \\
\text { Delta }=0,00 \mathrm{Gamma}=1,00\end{array}$ \\
\hline
\end{tabular}


Table 1 (cont.). Forecast Models of Exponential Smoothing of Statistical Indicators ("Trust in Vaccination against COVID-19", "Trust in Vaccination", "Vaccination against COVID-19")

\begin{tabular}{|l|l|l|}
\hline & VC4 & $\begin{array}{l}\text { Exponential smoothing: Multipl. Season (24) S0=16,03 } \\
\text { No trend,mult.season; Alpha=0,00 Delta=0,00 }\end{array}$ \\
\cline { 2 - 3 } & VC5 & $\begin{array}{l}\text { Exp. Smoothing: Multipl. Season (24) S0=15,38 T0=,0103 Lin.trend,mult.season; Alpha=0,00 } \\
\text { Delta=0,00 Gamma=0,00 }\end{array}$ \\
\cline { 2 - 4 } & VC6 & $\begin{array}{l}\text { Exp. Smoothing: Multipl. Season (24) S0=15,06 T0=1,002 Expon.trend,mult.season; Alpha= ,036 } \\
\text { Delta=0,00 Gamma=,186 }\end{array}$ \\
\hline
\end{tabular}

Source: Compiled by the authors

As a result of the study, seasonal components with a periodicity of two weeks were identified in all three time series. These results are presented in Table 2.

Table 2. Seasonal Factors of Statistical Indicators ("Trust in Vaccination against COVID-19", "Trust in vaccination", "Vaccination against COVID-19")

\begin{tabular}{|c|c|c|c|}
\hline $\begin{array}{c}\text { Case/ } \\
\text { Model }\end{array}$ & $\begin{array}{c}\text { Trust in vaccination against } \\
\text { COVID-19 }\end{array}$ & Trust in vaccination & Vaccination against COVID-19 \\
\hline 1 & $-3,95181$ & $-3,54599$ & $-3,96790$ \\
\hline 2 & 2,94805 & 3,29124 & 2,98779 \\
\hline 3 & $-5,34986$ & $-5,91099$ & $-5,33408$ \\
\hline 4 & $-0,24464$ & 0,29164 & $-0,24283$ \\
\hline 5 & $-5,35297$ & $-4,90419$ & $-5,33183$ \\
\hline 6 & 1,76003 & 2,20414 & 1,76100 \\
\hline 7 & 2,88928 & 3,50447 & 2,80933 \\
\hline 8 & $-2,48972$ & $-2,03753$ & $-2,39308$ \\
\hline 9 & 4,72528 & 5,16681 & 4,55383 \\
\hline 10 & $-0,51764$ & 0,16914 & $-0,50650$ \\
\hline 11 & 6,72553 & 7,18997 & 6,63883 \\
\hline 12 & $-4,97322$ & $-4,36203$ & $-4,95950$ \\
\hline 13 & 3,01187 & 3,40103 & 3,06446 \\
\hline 14 & $-5,01521$ & $-4,53814$ & $-4,92096$ \\
\hline 15 & 2,05951 & 2,52936 & 2,01196 \\
\hline 16 & $-6,24375$ & $-5,75480$ & $-6,35492$ \\
\hline 17 & 0,64597 & 1,05749 & 0,69182 \\
\hline 18 & 3,00597 & 3,33499 & 2,98099 \\
\hline 19 & $-0,34764$ & 0,13221 & $-0,35200$ \\
\hline 20 & 1,59180 & $-8,22057$ & 1,53821 \\
\hline 21 & $-1,82722$ & $-1,33501$ & $-1,68263$ \\
\hline 22 & 5,25722 & 5,64721 & 5,29140 \\
\hline 23 & $-2,65097$ & $-2,13967$ & $-2,70790$ \\
\hline 24 & 4,34416 & 4,82922 & 4,42453 \\
\hline
\end{tabular}

Source:Compiled by the authors

Based on the data in Table 1, the forecast models of exponential smoothing based on "Trust in vaccination against COVID-19" are constructed:

$$
\begin{aligned}
& \text { TC } 1_{t}=Y_{t-1}+I_{t-p}, I_{t}=I_{t-p}, S_{0}=15,52 \\
& \text { TC } 2_{t}=L T_{t}+Y_{t-1}+I_{t-p}, I_{t}=I_{t-p}, S_{0}=15,41, T_{0}=0,0071 \\
& \text { TC } 3_{t}=\mathrm{E} T_{t}+Y_{t-1}+I_{t-p}, I_{t}=I_{t-p}, S_{0}=15,06, T_{0}=1,002 \\
& \text { TC } 4_{t}=Y_{t-1} I_{t-p}, I_{t}=I_{t-p}, S_{0}=15,92 \\
& \text { TC } 5_{t}=L T_{t}+Y_{t-1} I_{t-p}, I_{t}=I_{t-p}, S_{0}=15,41, T_{0}=0,0071 \\
& \text { TC } 6_{t}=\mathrm{E} T_{t}+Y_{t-1} I_{t-p}, I_{t}=I_{t-p}, S_{0}=15,06, T_{0}=1,002
\end{aligned}
$$

where

TC $1_{t}$ - additive model of seasonality;

TC $2_{t}$ - trend-seasonal additive model;

TC $3_{t}-$ trend-seasonal additive model;

TC $4_{t}$ - multiplicative model of seasonality;

TC $5_{t}$ - trend-seasonal multiplicative model;

TC $6_{t}$ - trend-seasonal multiplicative model;

$L T_{t}$ - linear trend (value at time t);

$\mathrm{E} T_{t}$ - exponential trend (value at time $\mathrm{t}$ ). 
The ratio of theoretical levels calculated by formulas (8), actual data and model rests are presented in Figures 3-5.
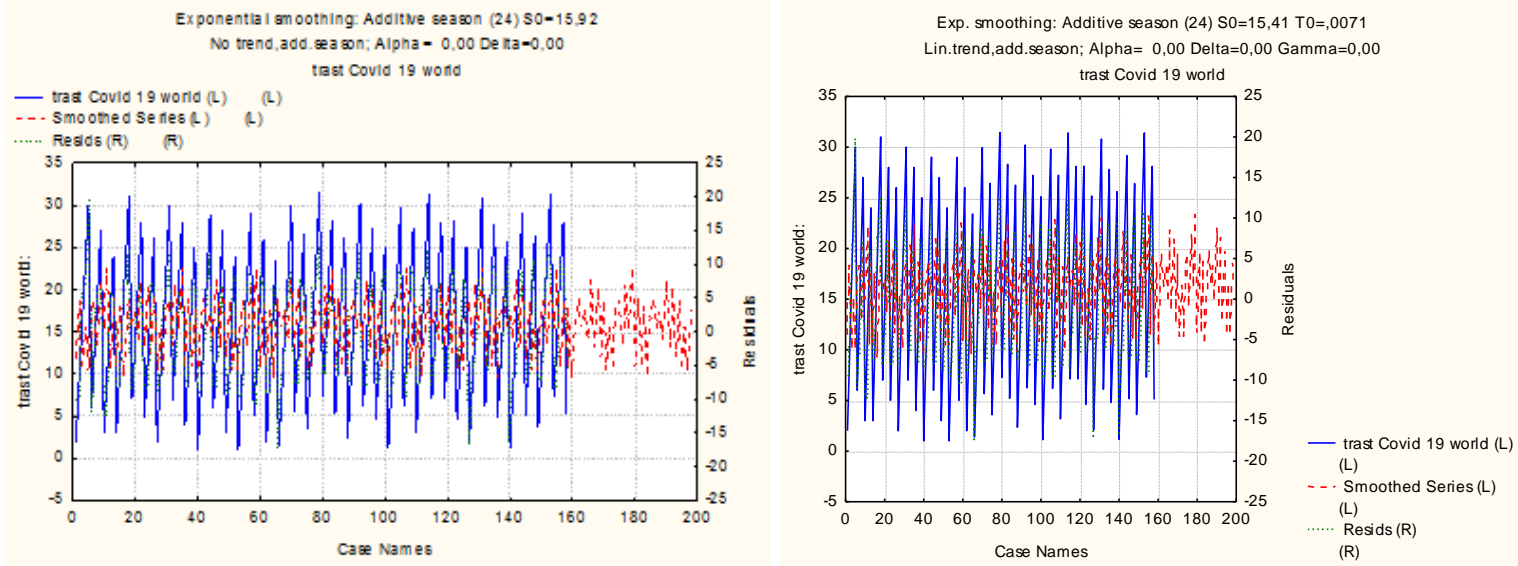

Figure 3. Actual and Forecast Levels of the Indicator "Trust in Vaccination Against COVID-19" (Left Fragment - Additive Seasonality Model, Right Fragment - Trend-Seasonal Additive Model)

Source:Compiled by the authors
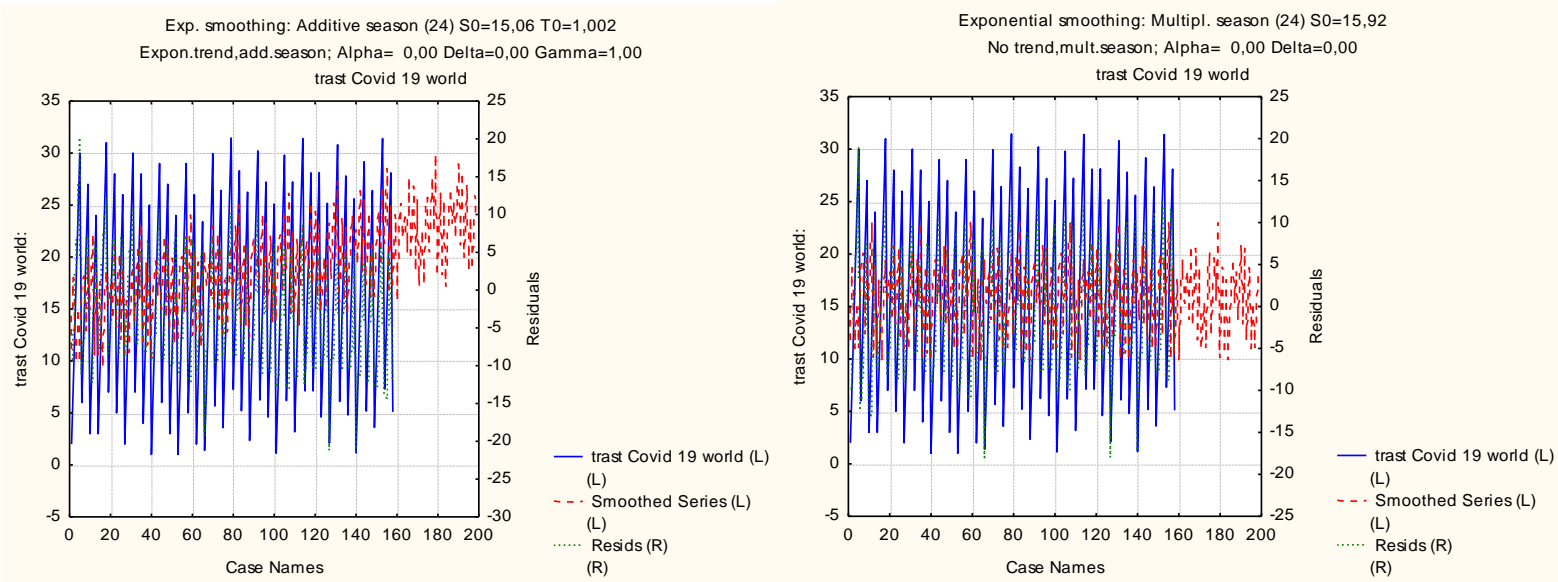

Figure 4. Actual and Forecast Levels of the Indicator "Trust in Vaccination Against COVID-19" (Left Fragment - TrendSeasonal Additive Model, Right Fragment - Multiplicative Model of Seasonality)

Source: Compiled by the authors
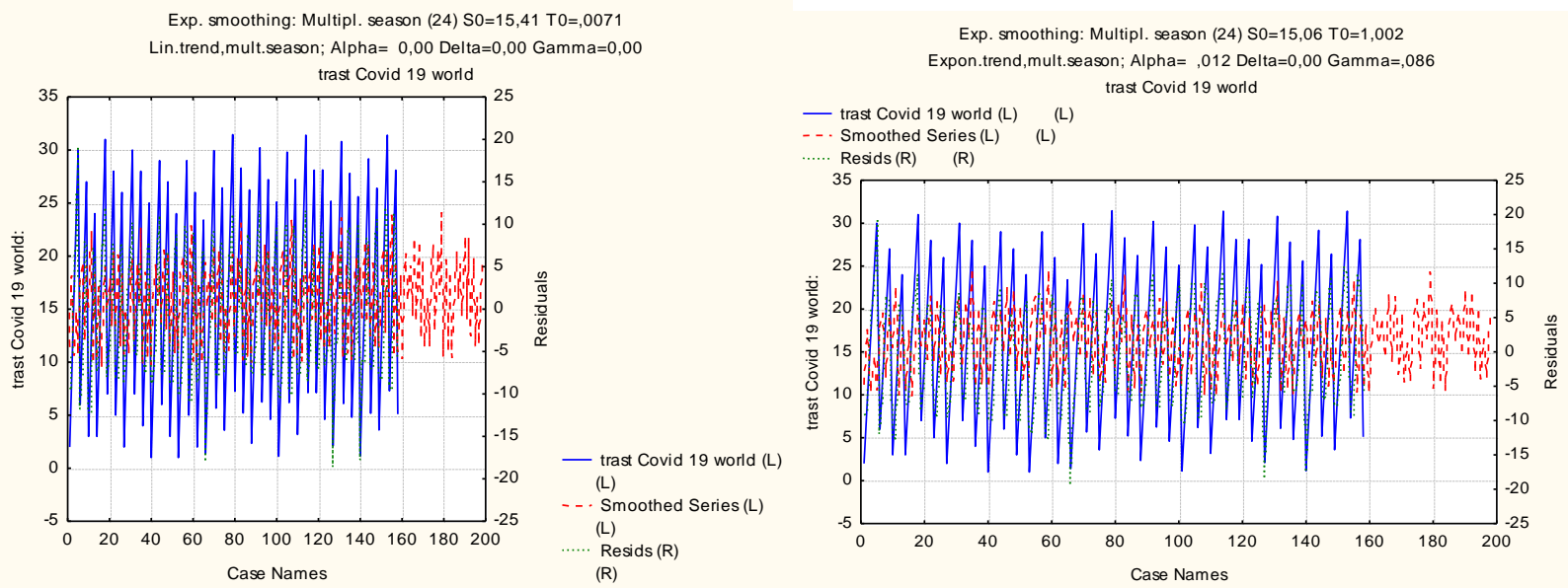

Figure 5. Actual and Forecast Levels of the Indicator "Trust in Vaccination Against COVID-19" (Left Fragment - TrendSeasonal Multiplicative Model, Right Fragment - Trend-Seasonal Multiplicative Model)

Source: Compiled by the authors

Data in Table 1 help to form predictive exponential smoothing models based on the indicator "Trust in vaccination":

$$
\begin{aligned}
\mathrm{TV} 1_{t}= & Y_{t-1}+I_{t-p}, I_{t}=I_{t-p}, S_{0}=15,38 \\
& \mathrm{TV} 2_{t}=L T_{t}+Y_{t-1}+I_{t-p}, I_{t}=I_{t-p}, S_{0}=15,47, T_{0}=0,0066
\end{aligned}
$$




$$
\begin{aligned}
& \mathrm{TV} 3_{t}=\mathrm{E} T_{t}+Y_{t-1}+I_{t-p}, I_{t}=I_{t-p}, S_{0}=15,41, T_{0}=0,0113 \\
& \operatorname{TV} 4_{t}=Y_{t-1} I_{t-p}, I_{t}=I_{t-p}, S_{0}=15,38 \\
& \operatorname{TV~} 5_{t}=L T_{t}+Y_{t-1} I_{t-p}, I_{t}=I_{t-p}, S_{0}=15,47, T_{0}=0,0066
\end{aligned}
$$

where

TV $1_{t}$ - additive model of seasonality;

TV $2_{t}$ - trend-seasonal additive model;

TV $3_{t}$ - trend-seasonal additive model with a declining trend;

$\mathrm{TV} 4_{t}-$ multiplicative model of seasonality;

TV $5_{t}$ - trend-seasonal multiplicative model;

$L T_{t}$ - linear trend (value at time t);

$D T_{t}$ - decaying trend (value at time t).

Visualization of the theoretical levels ratio calculated by formulas (9), actual data and model rests is presented in Figures 6-8.
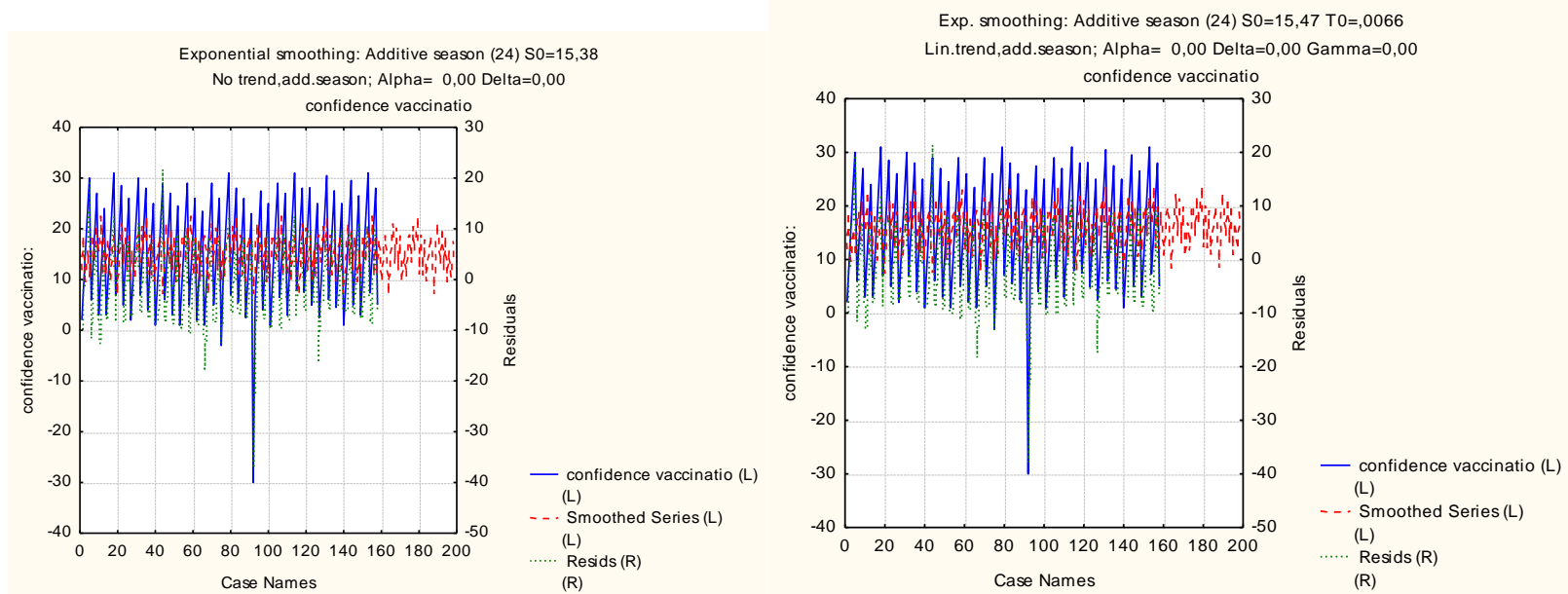

Figure 6. Actual and Forecast Levels of the Indicator "Trust in Vaccination" (Left Fragment - Additive Seasonality Model, Right Fragment - Trend-Seasonal Additive Model)

Source: Compiled by the authors
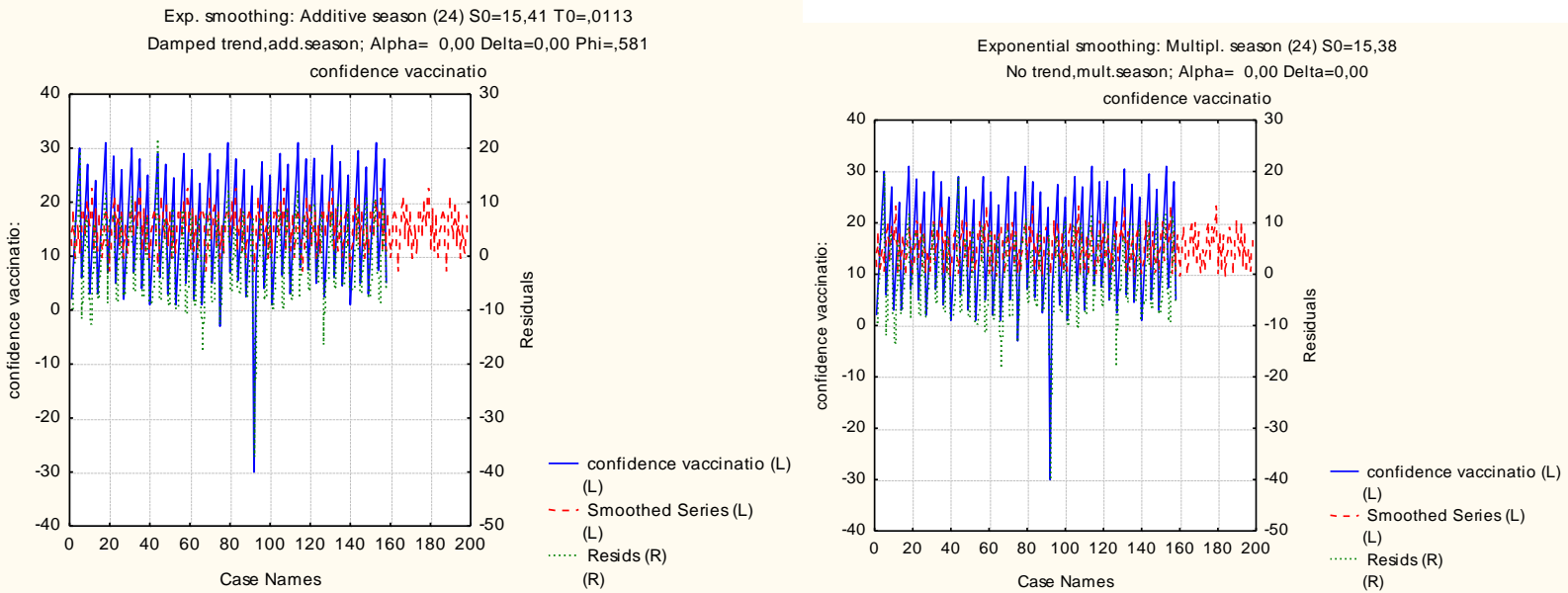

Figure 7. Actual and Forecast Levels of the Indicator "Trust in Vaccination" (Left Fragment - Trend-Seasonal Additive Model with a Declining Trend, Right Fragment - Multiplicative Model of Seasonality)

Source: Compiled by the authors 


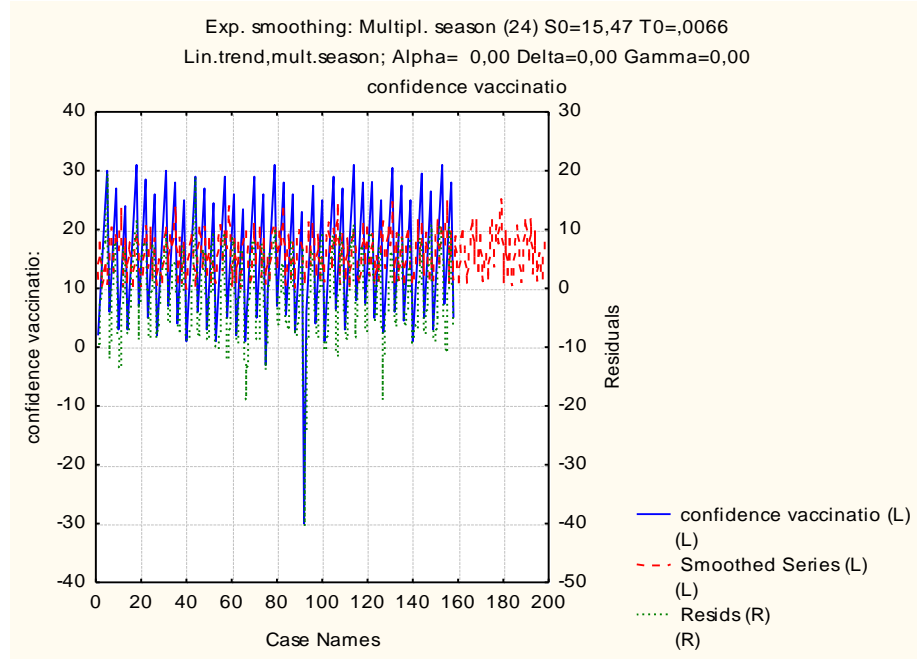

Figure 8. Actual and Forecast Levels of the Indicator "Trust in Vaccination", Trend-Seasonal Multiplicative Model Source: Compiled by the authors

Data from the Table 1 help to construct the predictive exponential smoothing models based on the indicator "Vaccination against COVID-19".

$$
\begin{aligned}
V C 1_{t}=Y_{t-1} & +I_{t-p}, I_{t}=I_{t-p}, S_{0}=16,03 \\
& \operatorname{VC~} 2_{t}=L T_{t}+Y_{t-1}+I_{t-p}, I_{t}=I_{t-p}, S_{0}=15,38, T_{0}=0,0103 \\
& \operatorname{VC~} 3_{t}=\mathrm{E} T_{t}+Y_{t-1}+I_{t-p}, I_{t}=I_{t-p}, S_{0}=15,06, T_{0}=1,002 \\
& V \mathrm{~V} 4_{t}=Y_{t-1} I_{t-p}, I_{t}=I_{t-p}, S_{0}=16,03 \\
& \operatorname{VC~} 5_{t}=L T_{t}+Y_{t-1} I_{t-p}, I_{t}=I_{t-p}, S_{0}=15,38, T_{0}=0,0103 \\
& \operatorname{VC~} 6_{t}=\mathrm{E} T_{t}+Y_{t-1} I_{t-p}, I_{t}=I_{t-p}, S_{0}=15,06, T_{0}=1,002
\end{aligned}
$$

where

VC $1_{t}$ - additive model of seasonality;

$\mathrm{VC} 22_{t}$ - trend-seasonal additive model;

$\mathrm{VC} 3_{t}-$ trend-seasonal additive model;

VC $4_{t}-$ multiplicative model of seasonality;

$\mathrm{VC} 5_{t}$ - trend-seasonal multiplicative model;

VC $6_{t}$ - trend-seasonal multiplicative model;

$L T_{t}$ - linear trend (value at time t);

$\mathrm{E} T_{t}$ - exponential trend (value at time t).

Figures 9-11 demonstrates the ratio between theoretical levels, calculated by formulas (10), actual data and model's rests represented in Figs. 9-11.
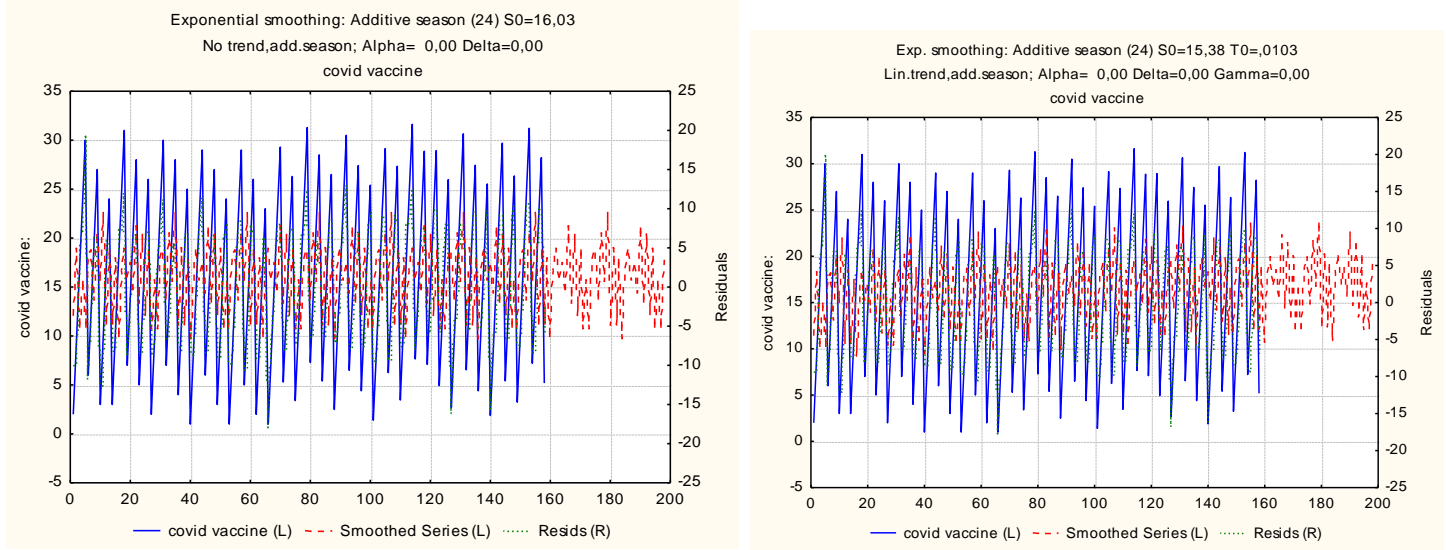

Figure 9. Actual and Forecast Levels of the Indicator "Vaccination Against COVID-19" (Left Fragment - Additive Seasonality Model, Right Fragment - Trend-Seasonal Additive Model)

Source: Compiled by the authors 

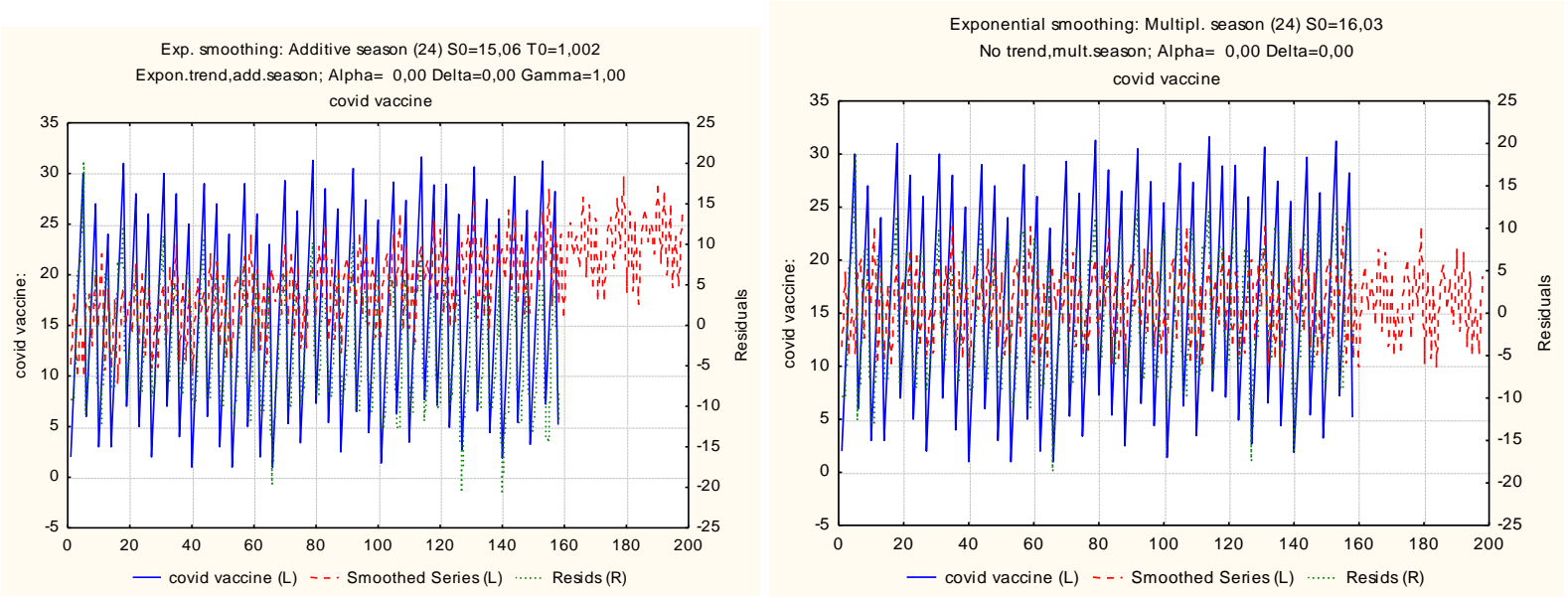

Figure 10. Actual and Forecast Levels of the Indicator "Vaccination Against COVID-19" (Left Fragment - Trend-Seasonal Additive Model, Right Fragment - Multiplicative Seasonality Model)

Source: Compiled by the authors
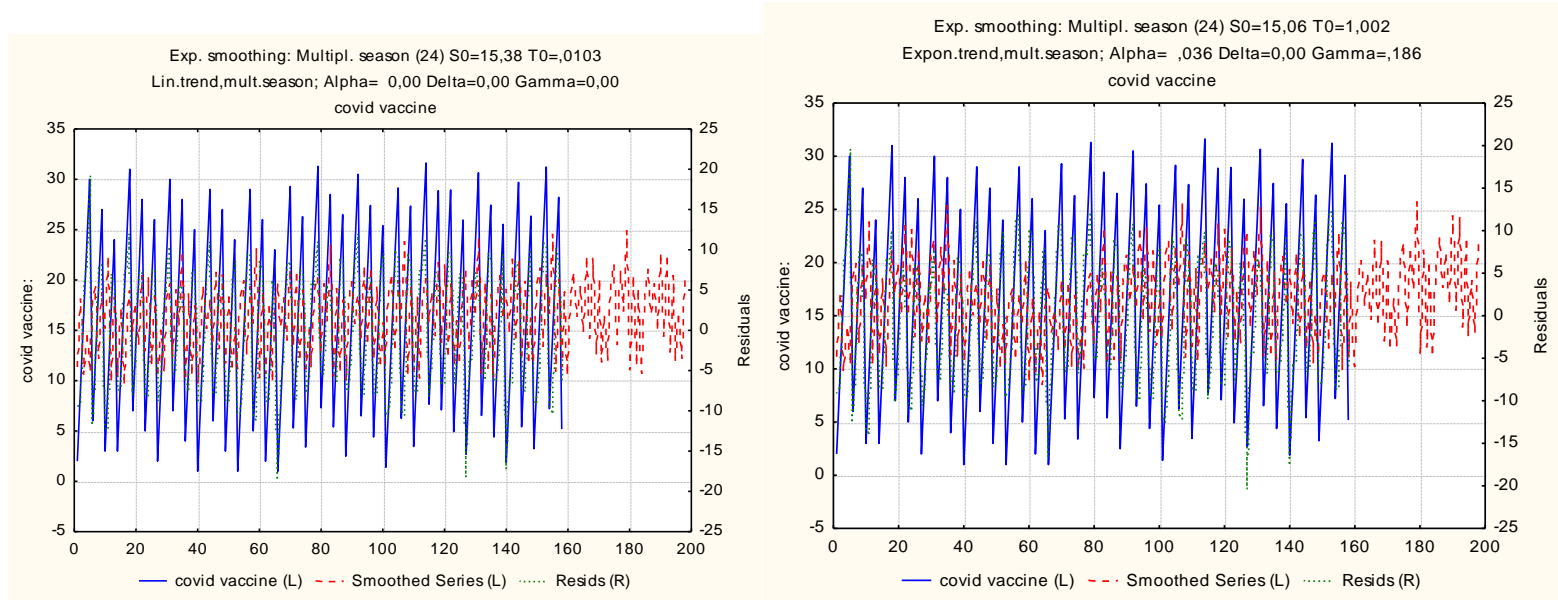

Figure 11. Actual and Forecast Levels of the Indicator "Vaccination Against Covid-19" (Left Fragment - Trend-Seasonal Multiplicative Model, Right Fragment - Trend-Seasonal Multiplicative Model)

Source: Compiled by the authors

The study of the time series structure - inquiries of Internet users on the issues of "Trust in vaccination against COVID-19", "Vaccination against COVID-19", "Trust in vaccination" suggests that all-time series have a seasonal component. The seasonal component reflects the recurrence of the process of Internet inquiries on the concepts of "Trust in vaccination against COVID-19", "Vaccination against COVID-19", "Trust in vaccination" for two weeks. In the general case, the seasonal component is associated with factors that act with a short periodicity. In contrast to the trend component, the seasonal has a growth phase and decline in each period. Its cyclical nature is associated with active fluctuations. The presence of a seasonal component must be considered when developing measures to increase public confidence in vaccination against COVID-19.

\section{Conclusions}

The results of the study show that the key factors influencing the vaccination process against COVID-19 are:

1) capacity of vaccination services for vaccine delivery and storage;

2) well-organized conditions for vaccination, in particular for at-risk groups;

3) easy access to vaccines for different target groups;

4) state communication policy on the benefits, risks and importance of vaccination;

5) uniting the efforts of many stakeholders, including state institutions in the health care, government, civil society, local communities;

6) public confidence in state institutions and the expert community.

People's trust in vaccination ensures public health during a pandemic. The level of trust in vaccination is influenced by various psychological, social and economic factors, including trust in official information. Declining trust in government, health care, social institutions and the media significantly affects the 
effectiveness of pandemic containment. The following factors contribute to increasing the level of trust in medical institutions, authorities on vaccination of the population:

1) effective communication of medical institutions and authorities with population on the impact of vaccination on the course of COVID-19, on the possible consequences of vaccination in risk groups, on the risks of COVID-19 in the absence of vaccination;

2) increasing the media literacy of the population;

3) creation of state information resources to publish the results of scientific research on the development of vaccines, on the course of COVID-19, the results of modeling the impact of vaccination on the spread of the pandemic, etc.

The study of time series shows that the proposed exponential smoothing method of time series is influential in determining the structure of the series and building predictive models of time series. The proposed technique can be used to analyze other time series, in particular when studying the level of public trust in vaccination based on the statistical data obtained from surveys.

Author Contributions: Conceptualization: Olha Kuzmenko and Svitlana Kolomiiets; methodology: Olha Kuzmenko; software: Olha Kuzmenko and Svitlana Kolomiiets; validation: Olha Kuzmenko and Svitlana Kolomiiets; formal analysis: Olha Kuzmenko and Svitlana Kolomiiets; investigation: Olha Kuzmenko and Svitlana Kolomiiets; writing-original draft: Svitlana Kolomiiets; writing-review and editing: Svitlana Kolomiiets; visualization: Olha Kuzmenko and Svitlana Kolomiiets; supervision: Olha Kuzmenko; project administration: Olha Kuzmenko.

Funding. There is no funding for this research.

\section{References}

1. Behavioural considerations for acceptance and uptake of COVID-19 vaccines: WHO Technical Advisory Group on Behavioural Insights and Sciences for Health, meeting report, 15 October 2020. Geneva: World Health Organization; 2020. Licence: CC BY-NC-SA 3.0 IGO. Available at: [Link]

2. Karlsson, L.C., Soveri, A., Lewandowsky, S., Karlsson, L., Karlsson, H., Nolvi, S., Karukivi, M., Lindfelt, M., Antfolka, J. (2021). Fearing the disease or the vaccine: The case of COVID-19. Pers Individ Dif, 172, 110590. [Google Scholar] [CrossRef]

3. Makusheva, M.O., Nestik, T.A. (2020) Socio-Psychological Preconditions and Effects of Trust in Social Institutions in a Pandemic. Monitoring of Public Opinion: Economic and Social Changes, 6. 427-447. [Google Scholar] [CrossRef]

4. Societal attitudes analysis to vaccination against COVID-19 in selected CAREC countries. Analytical report. Available at: [Link]

5. Панденоміка Європи: політичні, економічні та соціальні виклики вакцинування від COVID-19. Аналітична записка програм Європейських студій та Економічної дипломатії Ради зовнішньої політики «Українська призма» в рамках проекту Інституційного розвитку аналітичних центрів за підтримки Посольства Швеції в Україні, Ініціативи відкритого суспільства для Європи (OSIFE) та Міжнародного фонду «Відродження». [Pandenomika Yevropy: politychni, ekonomichni ta sotsial'ni vyklyky vaktsynuvannya vid COVID-19. Analitychna zapyska prohram Yevropeys'kykh studiy ta Ekonomichnoyi dyplomatiyi Rady zovnishn'oyi polityky «Ukrayins'ka pryzma» v ramkakh proektu Instytutsiynoho rozvytku analitychnykh tsentriv za pidtrymky Posol'stva Shvetsiyi v Ukrayini, Initsiatyvy vidkrytoho suspil'stva dlya Yevropy (OSIFE) ta Mizhnarodnoho fondu «Vidrodzhennya»] Available at: [Link]

6. Boyon, N. (2021). COVID-19 vaccination intent is decreasing globally. Ipsos. Available at: [Link]

7. Lazarus, J.V., Ratzan, S.C., Palayew, A. et al. (2021). A global survey of potential acceptance of a COVID-19 vaccine. Nat Med 27, 225-228. [Google Scholar] [CrossRef]

8. Rasskazova, E.I., Tkhostov, A.Sh. (2021). Eagerness to be vaccinated against coronavirus as an indicator of trust to official medical recommendations: the role of anxiety and beliefs. National Psychological Journal [Natsional'nyy psikhologicheskiy zhurnal], 14(1), 76-90. [CrossRef]

9. Steven, T., Caeleigh, A.L., Michelle, M.P., Rosalind, G., Geoffrey, S.R., \& Gordon, A.J. (2020). Proactive Approach for Managing COVID-19: The Importance of Understanding the Motivational Roots of Vaccination Hesitancy for SARS-CoV2. Frontiers in Psychology, 11, 2890. [Google Scholar] [CrossRef]

10.Tkhostov, A.Sh., Rasskazova, E.I. (2020). Psychological Contents of Anxiety and the Prevention in an Infodemic Situation: Protection against Coronavirus or the "Vicious Circle" of Anxiety? Konsul'tativnaya psikhologiya i psikhoterapiya [Counseling Psychology and Psychotherapy], 28(2), 70-89. [Google Scholar] 